Alberto Constante

\title{
Sade, el cuerpo obturado
}

Ignoran que también para el crimen existe una hora favorable.

Danton

¿Cuánto de Sade es liturgia o mito? ¿Cuánto de Sade vive ahora a través de sus libros y de su sombra? ¿Cuánto de ese fantasma y de esa pesadilla llamada Sade pervive dentro de la noción de mal que acarrea una historia de perversión, de fractura, de trasgresión y de intercambio en los cuerpos? Sade ha pasado a convertirse en un mito. $Y$ nos encontramos permanentemente frente a la formación de ese mito llamado Sade que no acaba por configurarse, no termina por aparecer, pero que, sin embargo, mantiene una presencia total, arrolladora porque en cierto modo, como dice Bataille, su presencia es "esencialmente la de una víctima". 1 Y no obstante, a la conformación de ese mito contribuyen los más antiguos recuerdos, las obsesiones más particulares, nuestros miedos más recónditos, el pensamiento moderno y sus aventuras con el pasado, las leyendas perdidas y la teología cristiana, todo amalgamado, con-

${ }^{1}$ Georges Bataille, L'Erotisme, ed. de Minuit, Colección Arguments, 1957, pp. 209-210. 
vertido en una sola materia que se constituye como la manifestación de una determinada visión, en la que encuentra su forma un pensamiento, alimentado por todos esos elementos, que se abre paso y encuentra su coherencia cediendo al carácter desorbitado y radical del ámbito en que puede manifestarse su sentido.

Porque Sade construye su mundo como antípoda y complementario de este mundo, Lacoste y Silling son símbolos de este espacio amurallado y solitario, de esa exclusión con la que el perverso y libertino vive y construye ese nuevo mundo reproduciendo "la historia del corazón". Aquí, los sueños y las pesadillas del artista, su propia fidelidad a las nostalgias que se encuentran en el origen de sus impulsos, se convierten en la materia que aloja un determinado pensamiento, cuya manifestación el arte hace posible entregándose como sustento. El pensamiento es ya una representación determinada por la fidelidad a las fuerzas impulsivas que se abren paso a través de las vías que les presta la cultura. Ese mundo constituye el " $d o-$ ble", del mundo, como señala Deleuze, en el que se recoge la violencia y el exceso. Por ello, "Sade representa la 'réplica' perversa del mundo, donde se refleja todo el movimiento de la naturaleza y de la historia". 2 Porque con el pensamiento moderno de hecho se abría la posibilidad de una nueva ironía, de una nueva forma de humor que quebrantaba la ley y el orden que esa misma modernidad establecía: "Las pasiones de mi vecino, nos dice Sade, son infinitamente menos temibles que la injusticia de la ley, porque esas pasiones son contenidas y contrarrestadas por las mías, mientras que nadie puede frenar las injusticias de la ley".

De esta suerte, la moral de Sade, nos recuerda Bataille citando a Blanchot, ${ }^{3}$

${ }^{2}$ Gilles Deleuze, Presentación de Sacher-Masoch, Ed. Taurus, Madrid, 1973.

${ }^{3}$ Georges Bataille, op. cit., p. 211. 
está fundada sobre el hecho primero de la soledad absoluta. Sade lo dijo y repitió bajo todas sus formas; la naturaleza nos hace nacer solos, no hay ninguna clase de relaciones entre un hombre y otro. La única regla de conducta, pues, es la de que prefiera todo lo que me afecte felizmente y la de que considera de nada todo lo que en mi preferencia pueda ser malo para el prójimo. El mayor dolor de los demás cuenta siempre menos que mi placer. ¿Qué importa si tengo que comprar el menor disfrute mediante un ensamblaje inaudito de fechorías? El disfrute me halaga, está en mí, pero el efecto del crimen no me atañe, está fuera de mí.

De ahí que nada más ridículo a este respecto que presentar la unión voluptuosa en términos de reciprocidad, de confusión de las identidades. Si bien es cierto que cada sexualidad arrastra a la otra, jamás existe reversibilidad entre dos que intercambian el sexo y menos todavía paso alternado del goce de un cuerpo a otro. Lo que el hombre y la mujer comparten no es una comunidad de intereses, de placeres, de pasiones o de fluidos, sino el gusto por su extrañeza recíproca, una mutua ignorancia insuperable. En lo más profundo del cuerpo, en lo más invisible de las cames, ningún espejo tiende con precisión su reflejo a uno y otro de los miembros de la pareja, evoca el espejismo de una complementariedad, como decía Platón en el Banquete; las emociones no se confunden.

Podríamos también pensar que el hombre pudiera, en la evanescencia de las reglas amorosas, olvidar su cabeza, perder su lucidez, entrar en un nuevo espacio de singularidades no mensurables, en fin, que pudiera escapar a la estrategia de la muerte y construir una ficción de una indiferenciación sexual y creer al sujeto del placer lo suficientemente generoso, lo suficientemente desencarnado para poder olvidar la parsimonia de sus propios circuitos eróticos.

La acmé voluptuosa no es el instante de la unión total entre los amantes, es, por el contrario, el punto de separación. Lo 
que Sade descubrió ante nosotros fue el hecho de que no hay posibilidad de una actitud soberana si ésta no se afirma con una inmensa negación, que la intimidad es percepción aguda de una distancia infranqueable, restablecimiento de una desviación, de una desnivelación profunda entre las personas; llevar a cabo el acto sexual equivale, entonces, de manera invariable, a separar y llevar a su máxima agudeza las mayores diferencias entre los seres. Para Sade, para el divino Marqués no existiría relación carnal sin esa inadecuación fundamental, esa impenetrabilidad absoluta en la que dos seres parten cada uno por su lado con sus inconfundibles pequeños goces.

La emoción voluptuosa que nos enseña el libertino es percepción de una rasgadura que no abre a nada, no permite comunicar, sino que se afirma para siempre jamás como división, desgarrón, catástrofe, y esa catástrofe hace que nos deseemos, que entre nosotros sólo existan disparidades, ninguna similitud. ¿Por qué el éxtasis del otro me excita tanto si no es porque abre entre él y yo la división irreductible de un mundo en el que el otro se desliza, y de unas regiones que siempre me resultarán desconocidas?

$Y$ es cierto que el rechazo del goce señala en el hombre un deseo evidente de conocer desde dentro la otra faz del mundo humano; es como un intento de transversalidad para establecer una comunicación entre sí de los sexos compartimentados. Si existe una ley de la intimidad amorosa, la hay en el sentido de que esta ley no reúne, no acerca en un todo sino que, por el contrario, regula los intervalos, los alejamientos, las separaciones. La desnudez no me acerca al otro, consagra nuestra separación; durante el acto sexual los seres no cesan de vivirse como unos seres discontinuos pero jamás su discontinuidad es tan hermética a todo paso, a toda fusión con el otro; por ello Juliette está abierta, sí, pero a su propia abertura, abierta al deseo de abrirse, interpelada, contemplada por la abertura del otro pero sin sacar de esa abertura ninguna facultad de trans- 
misión. La emoción es incomunicable. El amor es prueba exaltante de la elisión del otro.

Al configurar las voces de Juliette o de Justine, el lenguaje de Sade hace visible por completo la situación, los personajes que se mueven dentro de ella y el clima seductor y libertino, repulsivo y escatológico al mismo tiempo que esa situación produce. Los elementos grotescos y aun cómicos en el rompimiento entre el propósito que los guía y los obstáculos que encuentra su realización, la presencia imposible de disimular de una norma que se empeña en definir con términos peyorativos la conducta de los protagonistas, al tiempo que determinan la verosimilitud de la acción, deja entrever, contradictoriamente, la presencia de una grandeza a la que esos mismos elementos no permiten manifestarse plenamente, pero que, subrayando el tono enrarecido de la obra, determina la intensidad con que actúa sobre los nervios y el pudor del lector, despojándolo de sus defensas, obligándolo a entregarse al exacerbado ambiente abiertamente erótico y mostrando las transgresiones, que en esta obra maldita se nos hacen ver por dentro, con una forma tanto más perturbadora cuanto que no oculta nada y nos revela todo o, al menos nos revela a nosotros mismos. El otro no me es necesario más que para afirmar mi propia soberanía

Desde el punto de vista de la sociedad que determina las formas de vida y de conducta del mundo, la búsqueda de placer de Juliette la despersonaliza y la convierte en un objeto de cambio. Justine y Juliette, Eugenia de Franval o la Condesa de Sancerre, serán las figuras enajenadas por excelencia, manipuladas, sin voluntad, al servicio de los consumidores, adaptándose a sus exigencias. Y sin embargo, lo que los hace verdaderamente grandes como libertinos es el hecho de que pudieron aniquilar en ellos toda capacidad de gozo para el placer. Ellos se hicieron insensibles: pretenden gozar con su insensibilidad, con esa sensibilidad negada, aniquilada, que los convierten en seres fe- 
roces, insaciables. "La crueldad, dice Bataille, no es más que la negación de sí, llevada tan lejos que se transforma en una explosión destructora". 4 El bien intransferible que, como Sade nos dice, es la mujer entregada a la solicitud de los libertinos, satisfaciendo como objeto de cambio inclusive las exigencias deformadas de la perversión de quienes están prestos a obturar el cuerpo, a fragmentar el cuerpo, a llegar al crimen que no es más que la desaparición de los cuerpos. Y desde un punto de vista, la sociedad tiene razón; la perversidad crea un espacio cerrado, como el castillo de Silling, aunque sus efectos sean eternos:

Quisiera, dijo Clairwill, compañera de desenfreno de Juliette, encontrar un crimen cuyo efecto perpetuo actuase, incluso cuando yo dejara de actuar, de manera que no hubiese un solo instante de mi vida, en el que, incluso durmiendo, no fuese causa de un desorden cualquiera, y que ese desorden pudiese extenderse hasta el punto de que acarrease una corrupción general o un trastorno tan formal que más allá incluso de mi vida, se prolongase aún. ${ }^{5}$

El precio de ese espacio y de ese crimen es su aislamiento, su carácter exclusivo, su naturaleza excepcional, imposible de comunicar, como no sea en la tierra de nadie, en el espacio cerrado también del castillo, donde los sueños aparecen, se hacen visibles, pagando el precio de conservarse irrealizables, como sueños, como fantasías, como fantasmas convirtiéndose en presencias por la imaginación en el ámbito de lo imaginario. Preso de su sueño, el perverso vive de espaldas al mundo. Ajeno al progreso, al bien y la felicidad de los hombres, a la justicia, aislado en lo que de acuerdo con el juicio de la socie-

${ }^{4}$ Ibidem, pp. 240-241.

${ }^{5}$ Citado en M. Blanchot, Lautréamont et Sade, Ed. de Minuit, 1949, p. 244. 
dad que aspira a un bien común tendría que llamarse su inhumanidad, su absoluto egoísmo, del que Sade mismo se enorgullece, lo sitúa en el campo de la monstruosidad integral.

De acuerdo con los términos mismos de Sade, en última instancia, la perversidad absoluta, al negar la verdad de la identidad personal, niega toda la organización social, puesto que el movimiento mismo de la vida incluye la injusticia, incluye la presencia de la muerte; y este razonamiento de la perversidad, la hace también atea: la identidad personal sólo puede existir como reflejo de una identidad absoluta que le daría un alma inmortal y la destinaría a gozar o pagar eternamente por sus actos temporales, como lo afirma el cristianismo, pero esta posibilidad de goce o sufrimiento eternos descansa en la eliminación de todo sentimiento de justicia también, pues, si no, la vista de los condenados haría imposible el goce de los bienaventurados y si la eternidad es injusta, la temporalidad tiene que ser injusta. No hay alma individual inmortal, no hay identidad; no hay más que vida asentada en la naturaleza y, por lo tanto, muerte e injusticia en tanto realidad de la vida: el perverso tiene así que afirmar su derecho a la perversidad. La felicidad es ceguera y la perversidad acepta como culminación su propio sacrificio: la muerte en la que brillará y se mostrará la vida. "Quisiera que mis locuras me arrastraran hasta lo más degradante... El mismo patíbulo sería para mí trono de voluptuosidades" dice Borghese en Juliette. Porque el libertino se muestra excitado no por lo que está presente sino por lo ausente, no por las perversiones que se han dado sino por las que podría llevar a cabo, siempre a promesa de un goce mayor, de una apatía frente a la perversidad más grande. En este sentido es la idea del mal, la idea de la no presencia, la idea de la negación la que suministra la experiencia más dulce, porque para los personajes sádicos la insignificancia del crimen radica en la comparación con la idea que les dio origen. 
Nunca - como dice Foucault - la sexualidad ha tenido un sentido más inmediatamente natural ni ha conocido sin duda más 'feliz expresión' que el mundo cristiano del pecado y de los cuerpos caídos en desgracia. Toda una mística, toda una - espiritualidad lo prueban, y éstas no podrán desunir las formas continuas del deseo, de la embriaguez, de la penetración, del éxtasis y del desahogo que flaquea; sentían que todos esos movimientos se prosiguen, sin interrupción ni límite, hasta el corazón de un amor divino del que eran su último ensanchamiento y su fuente originaria de regreso. ${ }^{6}$

Sobre este mundo el divino Marqués escribía:

Me digo: existe un Dios, una mano ha creado lo que veo, pero para el mal; esta mano se complace en el mal; el mal es su esencia; todo lo que nos hace cometer es indispensable para sus planes [...]. El mal es necesario para la organización viciosa de este universo. Dios es muy vengativo, maligno e injusto. Las consecuencias del mal son eternas; en el mal ha crecido el mundo y por el mal se sostiene; también el mal lo perpetúa; e impregnada por el mal debe existir la criatura; y al seno del mal vuelve después la existencia. ${ }^{7}$

Sade pronuncia con más rigor el "Dios es el mal" de Proudhon. Porque es Sade quien formuló la más inequívoca profesión de ateísmo de su siglo.

Para Sade, si algo merece ser llamado Dios es el mal y él mismo le llamó así en ocasiones: "Veo el mal eterno y universal en el mundo. El mal es un ser moral increado; eterno, imperecedero; existía antes del mundo, constituía el ser monstruoso que pudo crear un mundo caprichoso. El autor del universo es el más maligno, el más feroz, el más horrendo de todos los seres". 8 Sade llamó

\footnotetext{
${ }^{6}$ Michael Foucault, Del lenguaje y literatura, ed. Paidós, Barcelona, 1996.

${ }^{7}$ Marqués de Sade, Juliette, vol. 2, pp. 341 y sigs.

8 Ibidem, p. 350.
} 
al mal con el nombre vacante de Dios. En el Día del Juicio Final, Sade imagina que Dios se dirigirá en estos términos al dulce rebaño de los virtuosos:

Cuando habéis visto que todo eras vicioso y criminal en la tierra -les dirá el Ser Supremo en Maldad - ¿por qué os habéis extraviado por los senderos de la virtud...? Y ¿cuál es pues el acto de mi conducta en que me habéis visto bienhechor? ¿Al enviaros pestes, guerras civiles, enfermedades, temblores de tierra, huracanes? Al sacudir perpetuamente sobre vuestras cabezas las serpientes de la discordia ¿os persuadía de que el bien es mi esencia? ¿Imbéciles? ¿Por qué no me imitábais?

Al hacer desaparecer la razón de Dios, este ateísmo significa que el principio de identidad mismo desaparece con el garante absoluto de ese principio y por tanto, la propiedad del yo responsable está moral y físicamente abolido. Primera consecuencia: la prostitución universal de los seres. Ésta no es sino la parte complementaria de la monstruosidad integral que reposa en la insubordinación de las funciones de vivir, en ausencia de una autoridad normativa de la especie. De alguna suerte, esta insubordinación es fundamental del pensamiento perverso: la sodomía, no en el sentido del gesto dirigido hacia alguno de la misma especie, sino en el original y mucho más amplio de deseo que busca y necesita saciarse conservando el carácter absoluto de su objeto y al evitar la reproducción, es siempre estéril.

El ateísmo y la perversión sadiana, el libertinaje destructor y la obturación de los cuerpos, el ceremonial de los suplicios encarnará perfectamente en Los ciento veinte días, pero igual en la Filosofía en la alcoba: aquí, siete diálogos. La cifra perfecta, el número sagrado es a la vez escarnio de los ritos, pero también institución de otro orden sagrado: el ateísmo del libertinaje: dos voces magisteriales, Eugenia, virgen de cuerpo y de 
alma pero muy bien dotada para las enseñanzas que se le van a dar, y Dolmancé, el perfecto maestro de la crueldad.

En el prólogo a Nietzsche y el círculo vicioso Klossowski nos hace aparecer identificados tanto Sade como Nietzsche como "filósofos del complot", pero nos preguntamos ¿cuál es ese complot al que se refiere el impío Klossowski? Ese complot nos lo aclara, es decir, utilizar el lenguaje del sentido para afirmar la ausencia de sentido: el imposible significado de lo que no tiene significación. El sentido del complot radica en la reiteración, en la repetición, en la vuelta sobre sí mismo, en su incapacidad de detenerse, pues en principio la búsqueda de Sade, si es que a esto pudiera llamársele búsqueda aparece como un despropósito. "El universo sadiano es un mundo de la reiteración sin fin, pero esta incansable repetición se sitúa en niveles diferentes y múltiples". ${ }^{9}$ Debe existir una máxima minuciosidad cuantitativa y cualitativa en los actos crueles y repugnantes, ahí es donde radica una de las fuentes de placer del libertino.

Una y otra vez, el deseo destruye al objeto del deseo, se reencuentra como deseo y reinicia su acción destructiva. Por ello, la posesión absoluta del objeto de un deseo absoluto es imposible sin un ultraje absoluto del objeto que trae consigo su destrucción. El personaje libertino busca desesperadamente por la repetición de sus actos, alcanzar ese absoluto, de ahí que Sade pueda pasar de su ceremonial del ultraje de los cuerpos al ceremonial del ultraje de las almas, tanto más cuanto que las almas son superiores y apasionadas, como en Crímenes del amor, donde no hay poca o ninguna violencia física, ninguna descripción erótica, ni siquiera alusiones, porque Sade está muy lejos del libertinaje y de la perversión ligeros; ahí, Sade prefiere describir el sufrimiento de la heroína que ve desde una ventana a su amante decapitado y no la tortura del infeliz sobre el patíbulo.

${ }^{9}$ Béatrice Didier, Sade, FCE, México, 1989, p. 136 (Breviarios). 
La permanencia de la monstruosidad integral, nacida como consecuencia de una determinada condición del mundo viene a depender de la repetición del ultraje, la reiteración del gesto único mediante el que la trasgresión del objeto del deseo se institucionaliza y lo ultrajado es mantenido. Es el rito, la ceremonia de los cuerpos, mediante la que triunfa la perversión. El pensamiento perverso, el único pensamiento al alcance del hombre sin centro, el pensamiento en el que se expresa una forma de vivir impuesta por la vida, vuelve a girar incansable sobre sí mismo, acumula energía para provocar la trasgresión y empezar de nuevo. Es un pensamiento maniático, un pensamiento del exceso; su órbita es la del círculo vicioso.

En todas y cada una de las novelas del Marqués podemos encontrar esa meticulosa precisión de hacernos cómplices de las perversidad, la complicidad para comunicarnos un contenido de experiencia considerado por las normas institucionalizadas como perverso y que por tanto desborda los límites impuestos por esas normas para hacer posible la comunicación. Dentro de la patología moderna podríamos decir que el perverso es un maniaco, porque el perverso persigue la ejecución de un gesto único. Para el perverso ejecutar ese gesto vale por la totalidad del hecho de existir.

En Filosofía en la alcoba, el ejemplo más demencial de esta manía lo podemos encontrar en el incesto, que es esencialmente una violación, un asesinato de la madre, en los antípodas del consentimiento y de la dicha. Aquí es el padre el que entrega la madre a la hija. Los incestos entre hermanos y hermanas no tienen ese resplandor, esa felicidad privilegiada de la relación padre-hija, porque el padre resulta doblemente poseedor, pues añade a sus derechos tradicionales sobre la hija, los del amante. El gozo fundamental del padre consiste en ver el reflejo de sí mismo en su hija, pero un reflejo lo suficientemente distinto para que pueda ser dominado. Es entonces cuando el disfrute es doble, a la vez del amo y de la esclava, fundidos en ese gozo único de la felici- 
dad narcisística y del onanismo, pero aligerado de toda tristeza, porque la soledad del incesto de Eugenia es la idea de evitar para siempre un contacto con un extraño: "Yo proseguía con calor, yo, unirme con un extraño que, no teniendo como tú dobles razones para amarme, pondría a la medida de sus sentimientos cuando más la de sus deseos".

Así pues, prisionero de la intensidad más fuerte, que le permite existir, el pensamiento sólo puede tener un carácter obsesivo; es un pensamiento maniaco: perverso. Y el gesto del perverso, en el que se manifestaría el pensamiento, no pertenece a ningún código; pero si ese gesto significa algo inteligible, si responde a una representación, si es un juicio, quiere decir que ese gesto interpreta algo. Esta divulgación establece una complicidad, pero lo hace en el terreno de lo incomunicable más allá del campo en el que se crea la complicidad, porque ese campo es el del placer, cuya naturaleza irracional no permite instituir ningún código común. El círculo de la comunicación permanece cerrado. Su capacidad de divulgación se basa en el hecho de que su lenguaje no busca tampoco una comunicación racional de acuerdo con las normas que han permitido instituirlo como lenguaje, sino que las trasgrede a través de los gestos y de las acciones que representa en su seno para entrar nuevamente en el círculo de la complicidad irracional. En el simulacro, el rito de dentro del que se representa el gesto único que crea el lenguaje del perverso, y que el arte hace suyo en tanto rito y simulacro, el lector ve desintegrarse su calidad de individuo razonable mediante un sobresalto de impulsión o de repulsión. Dentro de ese sobresalto, las normas de la razón se derrumban y triunfa la comunicación a través de la complicidad.

Un pensamiento nacido de la soledad extrema en que lo encierra la singularidad, pasa a hablar en nombre de la generalidad, al menos de su doble. Pero la obra en la que se muestra ese pensamiento nos prueba que el pensamiento siempre es solitario y singular. Ése es el único ámbito en el que puede 
existir. En esas condiciones, encontrar el pensamiento es comprobar la incoherencia del pensamiento y de la vida. Cuando la escritura ha llegado a ese grado de incandescencia es cuando puede cumplirse perfectamente la obra del novelista perverso, alimentándose de su propia fuerza, se comunica con el lector futuro señalando su destino: "esos escritores perversos cuya corrupción es tan perniciosa, tan activa, que no tienen por propósito, al imprimir sus horribles sistemas, sino prolongar más allá de su vida la suma de sus crímenes". Por ello, pudo exclamar el Divino Marqués: " $¡ S i g l o s$ por venir!, no veréis más ese colmo de horror y de infamia" porque este apotegma del Marqués no es más que uno de los extremos por donde transcurren nuestras vidas. 